\title{
DGS based Planar Inverted F Antenna for Multiband Applications
}

\author{
Y Sukanya, P.SaiSpandana, G.V Harshini, P.V.Y.JayaSree
}

\begin{abstract}
As Long Term Evaluation systems have more benefits when compared to other network systems, it became more popular. Integrating a lower band with a higher by considering space as a constraint became a challenge for designers. A simple PIFA (Planar Inverted F Antenna) with DGS(Defective Ground structure) is suggested inmultiple band applications. The proposed antenna is designed using the CST Microwave Suite 2017. The design is for substrate having $\varepsilon_{r}$ of 4.4(FR-4), (tan $\delta$ ) 0.02 as loss tangent with a thickness of $1.53 \mathrm{~mm}$ is preferred for designing of this antenna and is etched directly upon the substrate.
\end{abstract}

Keywords : Planar Inverted F Antenna,Defected Ground Structure (DGS), Multi band, Return Loss(RL).

\section{INTRODUCTION}

LTE (Long Term Evaluation) has been the main features of $4 \mathrm{G}$ mobile systems for enhanced broadband and multimode applications like GSM,UMTS.LTE has gained popularity among mobile network technologies. Applications of LTE in mobile phones and also in various types of computers has been very well recorded [1-9].

The compact size of the cellular phone with lower frequency LTE bands creates hurdles in the design of suitable antennas. have been widely experimented. For achieving desired characteristics, lot of effort goes in optimization of chosen design parameters. The chief aim of this research is to propose multiband characteristics for mobile handsets keeping in mind uncomplicated rules of design requires to attain minimal dimensions of satisfactory operation. For this purpose, DGS structure is with simple PIFA structure is preferred.

\section{DESIGN METHODOLOGY}

The size of the projected simple PIFA antenna has been displayed in figure 1. The design is carried out using CST Microwave studio suite 2017which works on FEM(Finite Element Method)using substrate of $\varepsilon_{\mathrm{r}}=4.4$ (FR-4), loss

Revised Manuscript Received on December 13, 2019.

* Correspondence Author

Mrs. Y Sukanya*, Department of E.C.E., Vignan's Institute of Information Technology(A), Visakhapatnam, India. Email: sukanyayadlapalli@gmail.com

Mrs. P. Sai Spandana, (Ph.D) Scholor, GITAM (Deemed to be University), Visakhapatnam, India.Email: psaispandana@gmail.com

G.V.Harshini, ECE Department, GITAM (Deemed to be University), Visakhapatnam, India. Email: harshini.ganti01@gmail.com

Dr. P.V.Y. Jaya Sree, Professor, GITAM (Deemed to be University),Visakhapatnam,India.Email: jayasree.pappu@gitam.edu tangent $(\tan \delta) 0.02$, (dielectricconstant) 4.4 with a thickness of $1.53 \mathrm{~mm}$ along with copper thickness of $0.035 \mathrm{~mm}$ were chosenfor making DGS and patch below and up side of the substrate. The simple antenna based on PIFA has been governed by the following equation with centre frequency of $2 \mathrm{GHz}$.

$$
f=\frac{c}{4(L 1-g X) \sqrt{\varepsilon_{r}}}(1)
$$

Where $\mathrm{f}=$ operating frequency

$L 1-g X=$ Length of antenna

$\varepsilon_{\mathrm{r}=\text { dielectric constant }}$

$\mathrm{C}=$ Velocity of Light

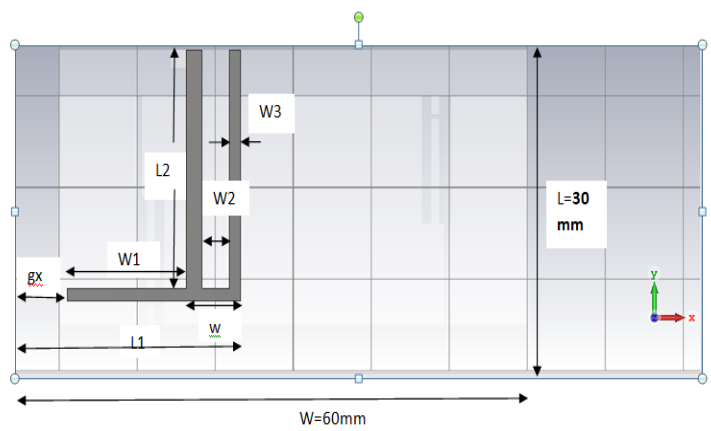

Figure 1: Geometry of the Proposed Antenna

1(a): Top View

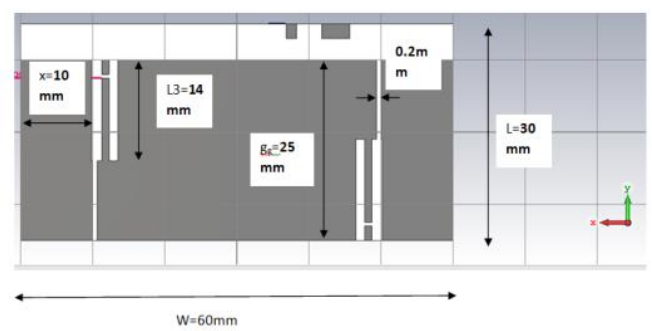

1(b): Bottom View

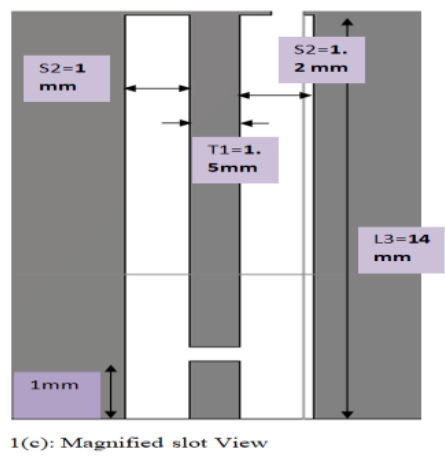


Table 1: Dimensions of the projected antenna

\begin{tabular}{|c|c|c|c|c|c|}
\hline $\begin{array}{l}\text { S } \\
\text { No }\end{array}$ & Parameter & $\begin{array}{c}\text { Val } \\
\text { ue(Mm } \\
)\end{array}$ & $\begin{array}{l} \\
\text { L. } \\
\mathbf{N} \\
\mathbf{O}\end{array}$ & Parameter & $\begin{array}{c}\text { Val } \\
\text { ue } \\
(\mathbf{M m})\end{array}$ \\
\hline 1 & $\begin{array}{l}\text { Length Of Gnd } \\
\text { Plane, } L\end{array}$ & 30 & $\begin{array}{r}9 \\
.\end{array}$ & $\begin{array}{l}\text { Thickness } \\
\text { of patch ,hp }\end{array}$ & $5^{.03}$ \\
\hline 2 & $\begin{array}{l}\text { Width OF Gnd } \\
\text { Plane, W }\end{array}$ & 60 & $\begin{array}{ll}1 \\
0 .\end{array}$ & Width, W1 & \\
\hline${ }^{3}$ & $\begin{array}{l}\begin{array}{r}\text { Distance from } \\
\text { edge, } g_{x}\end{array} \\
\end{array}$ & 10 & 1. & $\begin{array}{c}\text { Slot } \\
\text { distance from } \\
\text { edge }(\mathbf{X}), \mathbf{x}\end{array}$ & 10 \\
\hline${ }^{4}$ & $\begin{array}{l}\text { Width of patch, } \\
\text { L1-gX }\end{array}$ & 18 & $2^{1}$ & $\begin{array}{r}\text { Gap } \\
\text { between } \\
\text { slots,T1 } \\
\end{array}$ & $5^{1.2}$ \\
\hline 5 & $\begin{array}{l}\text { Width of } \\
\text { shorting Line ,W3 }\end{array}$ & 1.4 & 3. 1 & $\begin{array}{l}\text { Length of } \\
\text { slot,L3 }\end{array}$ & 14 \\
\hline . 6 & $\begin{array}{l}\text { Gap between } \\
\text { two lines, W2 }\end{array}$ & 3.5 & 4. 1 & $\begin{array}{l}\text { Width of } \\
\text { slot,S2 }\end{array}$ & \\
\hline 7 & , L2 $^{\text {Length of patch }}$ & 25 & 5.1 & $\begin{array}{l}\text { Length Of } \\
\text { Gnd, } g_{g}\end{array}$ & 25 \\
\hline & $\begin{array}{c}\text { Thickness } \\
\text { substrate ,hs }\end{array}$ & 1.53 & & & \\
\hline
\end{tabular}

According to principle of PIFA antenna, the required length of the Monopole antenna ( $\mathrm{L} 1-\mathrm{gX})$ equals $\chi / 4$ wave length and is about $18 \mathrm{~mm}$ at the frequency of $2 \mathrm{GHz}$. The dimensions of the proposed simple PIFA structure with DGS is given in table 1 .

\section{RESULTS AND DISCUSSIONS}

The simulation characteristics for without DGS is given in figure 2.This was resonating at 2 placeswith a $-6 \mathrm{~dB}$ impedance bandwidthfor the design shown in figure 1(a) at $1.87 \mathrm{GHz}$ and $3.22 \mathrm{GHz}$ with a RL of $-3.22 \mathrm{~dB}$ and $-6.4 \mathrm{~dB}$ respectively.

For further improvement of RL of the projected structure DGS structure is designed by etching various slots on the GNDhaddisplayed in fig.1(b).By etching slot 1(from bottom of the GND plane) another frequency is observed at $4.56 \mathrm{GHz}$ with a return loss of $-15 \mathrm{~dB}$ and also the frequencies of $1.87 \mathrm{GHz}$ and $3.22 \mathrm{GHz}$ is shifted to $1.69 \mathrm{GHz}$ and $2.77 \mathrm{GHz}$ with a return loss of $-5.67 \mathrm{~dB}$ and $-24.5 \mathrm{~dB}$ as shown in figure 3. Slot 2 (from top of the GND plane) is etched to have the same resonant frequencies with return loss of $-5 \mathrm{~dB},-19 \mathrm{~dB}$ and $-16 \mathrm{~dB}$ respectively as shown in figure 4 . Slot 3 is etched which is connected with slot 1 to make antenna to resonant at $2 \mathrm{GHz}$ so that the return loss is shifted to $-10 \mathrm{~dB},-6.92 \mathrm{~dB}$ and $-14.4 \mathrm{~dB}$ with frequencies of $2.057 \mathrm{GHz}, 3.1 \mathrm{GHz}$ and $4.38 \mathrm{GHz}$ respectively as shown in figure 5 . Similarly another slot is etched to connect with slot 2 to improve the performance further that results in appearance of another frequency at $3.76 \mathrm{GHz}$ with return loss of $-4.97 \mathrm{~dB}$ and also improved the return loss at the same frequencies as said before with slot 3 with return losses of $-15 \mathrm{~dB},-3.3 \mathrm{~dB}$ and $-12 \mathrm{~dB}$ as shown in figure 6.5 was etched to improve return loss for $4.39 \mathrm{GHz}$.By including this slot, the frequencies observed at $-6 \mathrm{~dB}$ bandwidth are $2.057 \mathrm{GHz}, 3.114 \mathrm{GHz}, \quad 3.767 \mathrm{GHz}$ and $4.39 \mathrm{GHz}$ with return loss of $-13.78 \mathrm{~dB},-6.7 \mathrm{~dB},-5.16 \mathrm{~dB}$ and $-12.54 \mathrm{~dB}$ respectively as shown in figure 7 . Similarly slot 6 is etched that causes the shifting of frequencies to $1.89 \mathrm{GHz}, 2.9 \mathrm{GHz}, 3.77 \mathrm{GHz}$ and $4.757 \mathrm{GHz}$ with return loss of $-10 \mathrm{~dB},-12.54 \mathrm{~dB},-3.3 \mathrm{~dB}$ and $-28.24 \mathrm{~dB}$ respectively as shown in figure8.

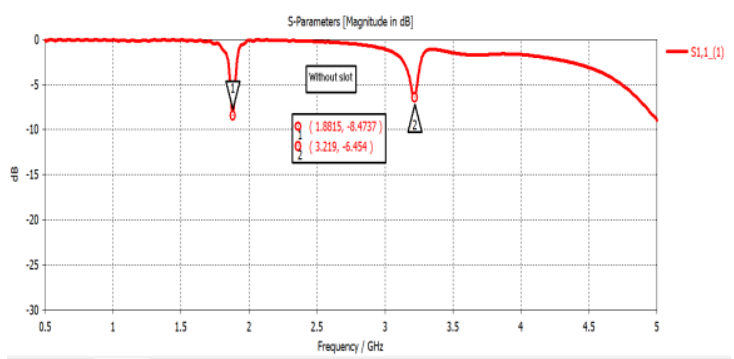

Figure 2: RL of projected antenna without slots

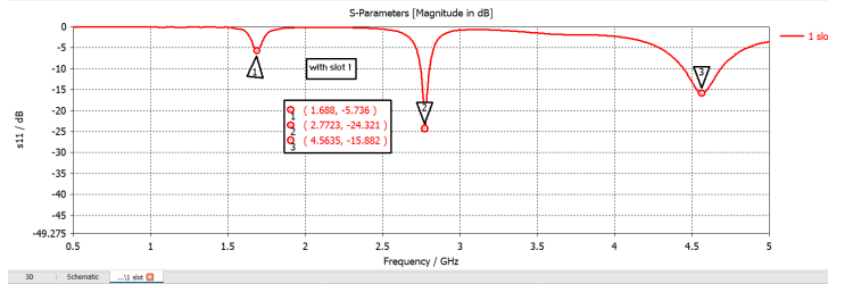

Figure 3: Return Loss of Proposed antenna with slot 1

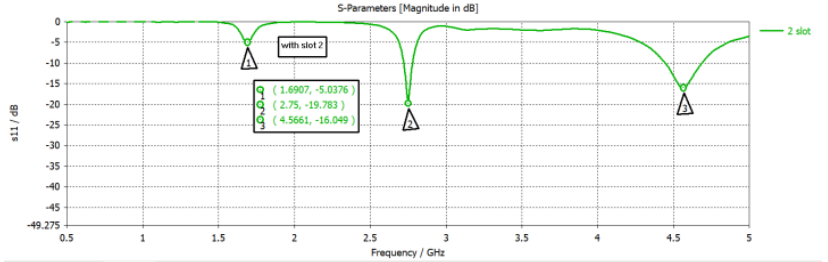

Figure 4: RL of projected antenna with slot 2

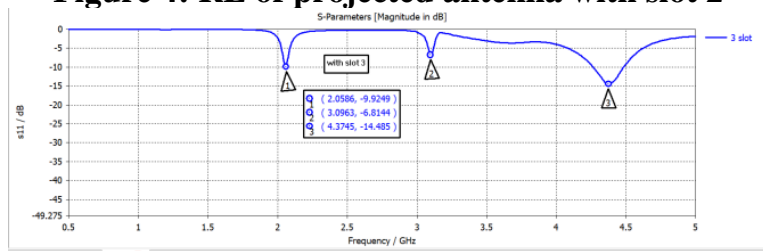

Figure 5: RL of projected antenna with slot 3

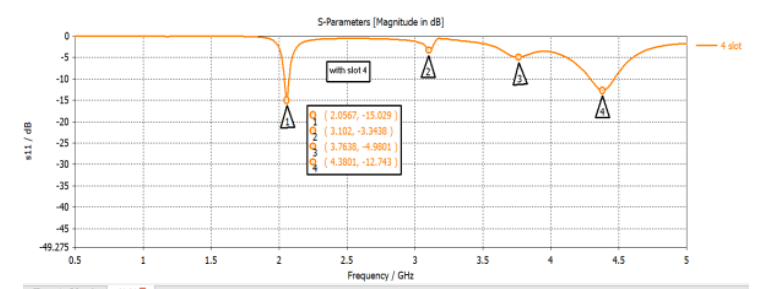

Figure 6: RL of projected antenna with slot 4

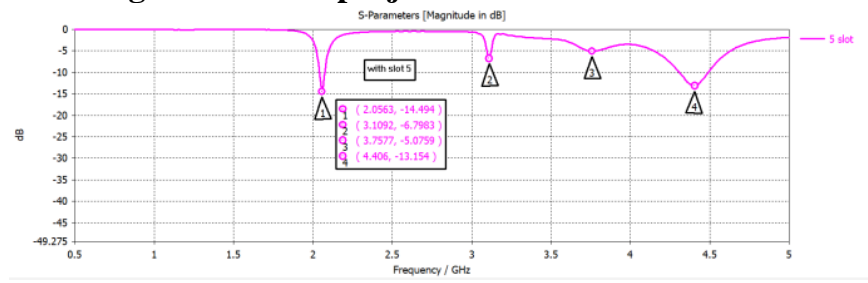

Figure 7: RL of projected antenna with slot 5

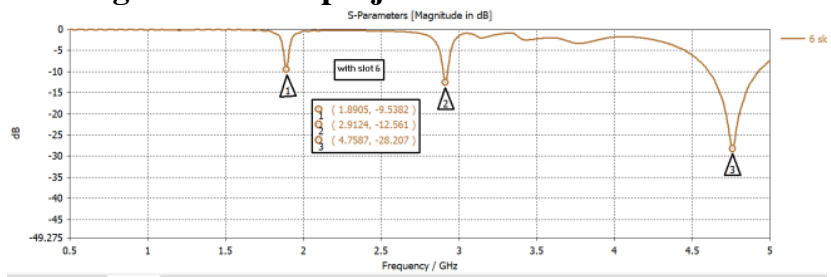

Figure 8: RL of projected antenna with slot 6 


\section{PARAMETRIC STUDY OF PROJECTED ANTENNA}

Parametric study was carried out to position the first slot for achieving better performance by varying the value of $x$ from 5 to 10 and the value is optimized for $10 \mathrm{~mm}$ from either side of the patch along $\mathrm{X}$ direction(width). Similarly parametric study was carried for length and width dimensions of slot and they are found to be $14 \mathrm{~mm}$ and $1 \mathrm{~mm}$ for better performance. The gap between the slots is also studied by varying it from $1 \mathrm{~mm}$ to $1.5 \mathrm{~mm}$ and the best value is found to be $1.25 \mathrm{~mm}$ between the slots shown in figure 9. With this gap, the antenna resonates at three frequencies as $1.8797 \mathrm{GHz}$, $2.912 \mathrm{GHz}$ and $4.82 \mathrm{GHz}$ at $-10 \mathrm{~dB}$ bandwidth there by covering $\mathrm{L}$ band, $\mathrm{S}$ band and $\mathrm{C}$ band respectively.For further improvement, horizontal slots were etched but there is no significant improvement for lower bands.

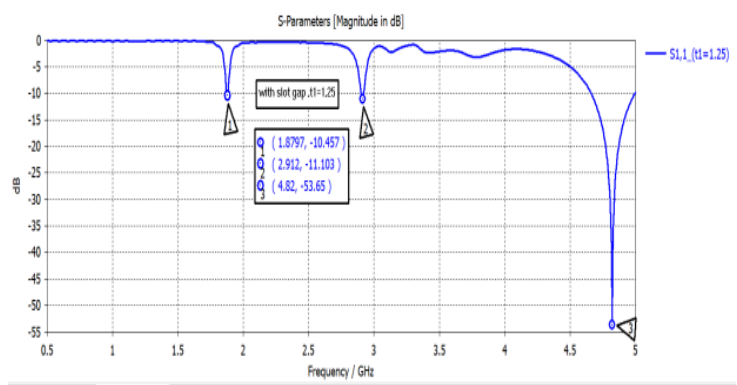

Figure 9: RL of projected antenna with gap between slots

\section{V.CONCLUSION}

In this paper, a simple PIFA with Defected Ground structure is proposed. By incorporating this structure, the operation of the antenna in terms of RL was improved in addition to exhibiting multiband characteristics which is suitable for $\mathrm{L}$ band, $\mathrm{S}$ band and $\mathrm{C}$ band applications.

\section{REFERENCES}

1. Wi, Hyunho, Byeongkwan Kim, Woojae Jung, and Byungje Lee. "Multiband handset antenna analysis including LTE band MIMO service." Progress In Electromagnetics Research 138 (2013): 661-673..

2. Zhao, Guo-Huang, An-Guo Wang, Wen Leng, Bin Chen, and Hua Chen. "Wideband internal antenna with coupled feeding for $4 \mathrm{G}$ mobile phone." Microwave and Optical Technology Letters 55, no. 3 (2013) 513-516.

3. Chu, Fang-Hsien, and Kin-Lu Wong. "Planar printed strip monopole with a closely-coupled parasitic shorted strip for eight-band LTE/GSM/UMTS mobile phone." IEEE Transactions on Antennas and Propagation 58, no. 10 (2010): 3426-3431.

4. A. Verma, "A novel quad band compact meandered PIFA antenna for GPS,UMTS, WiMAX, HiperLAN/2 applications," Second InternationalConference on Advances in Computing and Communication Engineering,2015.

5. Luhaib, SaadWasmi, Kaydar M. Quboa, and Bareq M. Abaoy. "Design and simulation dual-band PIFA antenna for GSM systems." In International Multi-Conference on Systems, Signals \& Devices, pp. 1-4. IEEE, 2012.

6. Marzudi, W. N. N. W., M. N. Z. Abidin, S. Z. M. Muji, Ma Yue, and Raed A. Abd-Alhameed. "Mutual coupling reduction of two elements antenna for wireless applications." (2014).

7. Redzwan, F. N. M., M. T. Ali, MN Md Tan, and N. F. Miswadi. "Design of tri-band Planar Inverted F Antenna (PIFA) with parasitic elements for UMTS2100, LTE and WiMAX mobile applications." In 2015 International Conference on Computer, Communications, and Control Technology (I4CT), pp. 550-554. IEEE, 2015.

8. Sun, Qiao, Baohua Sun, Ling Sun, Wei Huang, and Qiannan Ren. "Broadband two-element array with hybrid decoupling structures for multimode mobile terminals." IEEE Antennas and Wireless Propagation Letters 14 (2015): 1431-1434

\section{AUTHORS PROFILE}

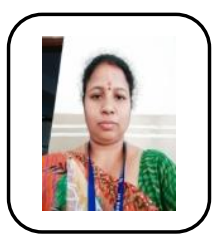

Mrs.Y.Sukanya is as an Associate Professor in Electronics and Communication Engineering Department from Vignan's Institute of Information Technology (A). Duvvada, Visakhapatnam. she is presently pursuing Ph.D from GITAM University at Visakhapatnam, obtained M. Tech in 2008 and B.E in 2001. Her research interests include Antennas and signal processing. 2001 nd 2008. She is working At present, she is working as a full-time research scholar at GITAM University, Visakhapatnam. Her research interests include EMI/EMC and Antennas.

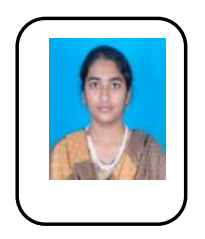

P. Sai Spandana completed her B.E and M.E degrees in Electronics and Communications Engineering and Embedded System Technologies from Anna University, Chennai in 2010 and 2015 respectively. She worked as an Assistant Professor in Electronics and Communication Engineering Department from Sridevi Women's Engineering College (Affiliated to JNTU-Hyderabad) from 2017 to 2019. At present, she is working as a full-time research scholar at GITAM University, Visakhapatnam. Her research interests include EMI/EMC and Antennas

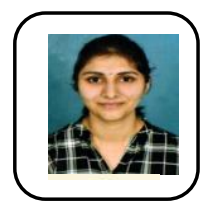

G.V. Harshini, studying B.Tech second year with CGPA 8.45 in the department of E.C.E, GITAM Institute of Technology, GITAM (Deemed to be University), Visakhapatnam

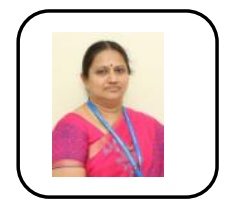

Dr.P.V.Y.Jayasree received her M.E. and Ph.D degrees in Electronics and Communications Engineering from Andhra University, Visakhapatnam and JNT University, Kakinada in 1999 and 2010 respectively. She is currently a Professor and Head of the Department of Electronics and Communications Engineering with GITAM University, Visakhapatnam, India. Her research interest lies in the areas of EMI/EMC, Antennas, Micro waves etc 